\title{
Wavelength Converters: Network Applications And Systems Experiments
}

Danielsen, Søren Lykke; Jørgensen, Carsten; Mikkelsen, Benny; Hansen, Peter Bukhave; Poulsen, Henrik Nørskov; Stubkjær, Kristian

Published in:

Lasers and Electro-Optics, 1997. CLEO '97., Summaries of Papers Presented at the Conference on

Publication date:

1997

Document Version

Publisher's PDF, also known as Version of record

Link back to DTU Orbit

Citation (APA):

Danielsen, S. L., Jørgensen, C., Mikkelsen, B., Hansen, P. B., Poulsen, H. N., \& Stubkjær, K. (1997).

Wavelength Converters: Network Applications And Systems Experiments. In Lasers and Electro-Optics, 1997. CLEO '97., Summaries of Papers Presented at the Conference on (Vol. 11). IEEE.

\section{General rights}

Copyright and moral rights for the publications made accessible in the public portal are retained by the authors and/or other copyright owners and it is a condition of accessing publications that users recognise and abide by the legal requirements associated with these rights.

- Users may download and print one copy of any publication from the public portal for the purpose of private study or research.

- You may not further distribute the material or use it for any profit-making activity or commercial gain

- You may freely distribute the URL identifying the publication in the public portal 
Electro-Optics, Vol. 8, 1994 OSA 'l'echnical Digest Series (Optical Society of America, Washington, DC, 1994), paper CThD6.

5. S. J. B. Yoo, C. Caneau, R. Bhat, M. A. Koza, A. Rajhel, N. Antoniades, Appl. Phys. Lett. 68, 2609 (1996).

6. S. J. B. Yoo, R. Bhat, C. Cancau, M. A. Koza, Appl. Phys. Lett. 66, 3410 (1995).

\section{CMF4 (Invited)}

9:30 am

Wavelength converters: network applications and systems experiments

S. L. Danielsen, C. Joergensen, B. Mikkelsen, P. B. Hansen, H. N. Poulsen, K. E. Stubkjaer, Center for Broadband Telecommunications, Dept. of Electromagnetics Systems, Technical University of Denmark, Building 348, DK-2800 Lyngby, Denmark; E-mail: sld@emi.dtu.dk

Wavelength converters will be implemented in future wavelength-division multiplexing (WDM) networks to improve the efficiency, throughput, and flexibility of the network. The converters will reduce wavelength blocking and allow for a distributed wavelength assignment that relaxes the management as well as eases the reconfiguration and protection of the network. Many research projects such as the ARPA MONET project therefore consider the use of wavelength converters and within the European ACTS research program both KEOPS and OPEN include wavelength converters in their switch block architectures.

An example of a switch architecture with wavelength converters is given in Fig. 1. The advantage of using the converters to avoid wavelength blocking at the switch output is illustrated in the figure.

The above example underlines the importance of developing efficient and practical alloptical wavelength converters. To be attractive for future networks the converters must fulfill a number of requirements: they should be bit-
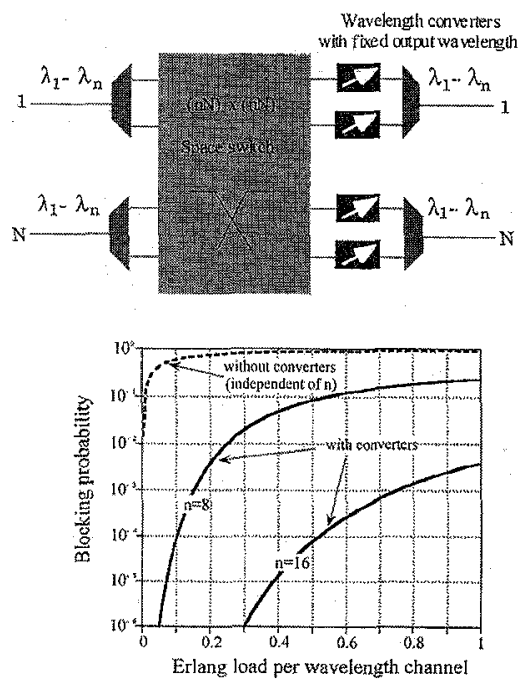

CMF4 Fig. 1 Top: Schematic of WDM switch block with wavelength converters. Bottom: Influence of wavelength conversion on the blocking probability of a $16 \times 16 \mathrm{WDM}$ cross-connect $(\mathrm{N}=16)$ with the number of wavelength channels, $n$, as the parameter.
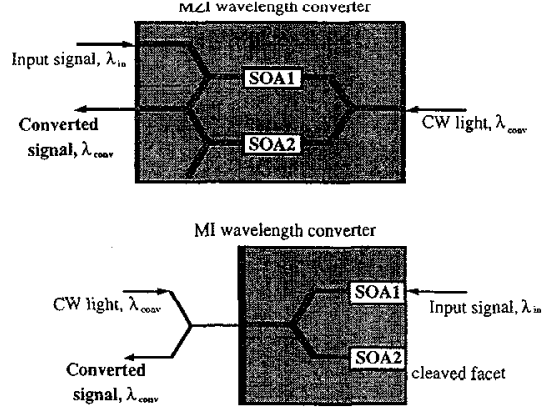

(a)

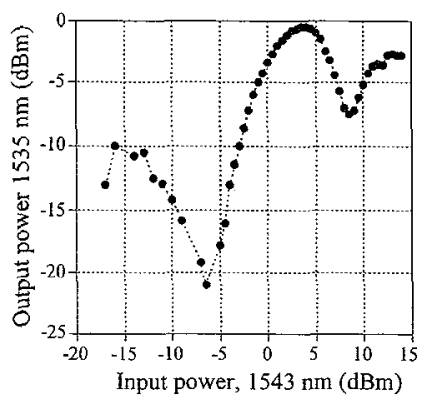

(b)

CMF4 Fig. 2 (a) Wavelength conversion principle using MZI and MI structures with SOAs. (b) Static transfer function of the MZI converter: Output power at $\lambda_{\text {conv }}=1535 \mathrm{~nm}$ versus input power at $\lambda_{\mathrm{in}}=1543 \mathrm{~nm}$. The bias current to SOA1 is $300 \mathrm{~mA}$ and $196 \mathrm{~mA}$ to SOA2.

rate transparent, polarization- and wavelengthindependent, give high extinction and signal-toASE ratios for the converted signals and only introduce a small chirp. Many useful techniques have been proposed and demonstrated; the most promising of these are based on cross-gain modulation (XGM) and cross-phase modulation (XPM) in SOAs and lasers. The advantages of XGM conversion is discussed but the reminder of the attention is on SOA-based XPM converters because of their superior performance. These converters rely on the modulation of the refractive index of SOAs placed in interferometric structures such as Michelson (MI) and Mach-Zehnder interferometers (MZI) [see Fig. 2(A)]. The semiconductor optical amplifiers hereby operate as phase shifters, which enables efficient wavelength conversion as described in Ref. 1. A static transfer characteristic is shown in Fig. 2(B) for a polarization-independent MZI made by Thomson-CSF in France.

XPM interferometric converters feature very high extinction ratios for the converted signals as well as wavelength independence and potentially also polarization independence and small chirp. The chirp introduced by XPM conversion even supports transmission over nondispersion-shifted fiber allowing transmission beyond the dispersion limit.

Given the above mentioned features, recent research has been devoted to the development of high-speed XPM converters (>10 Gbit/s). High speed can be obtained by using high input powers and high injection currents. Additionally, theoretical and experimental studies have shown that a high optical confinement factor and high differential gain for the SOAs

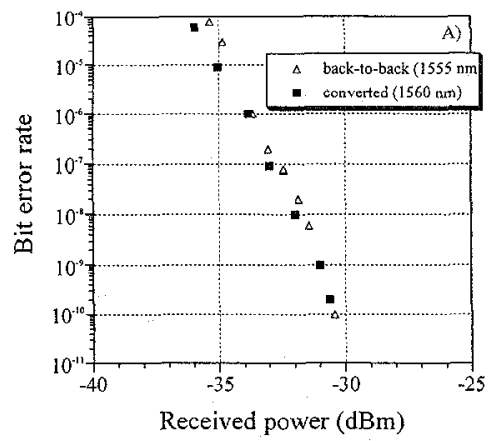

(a)

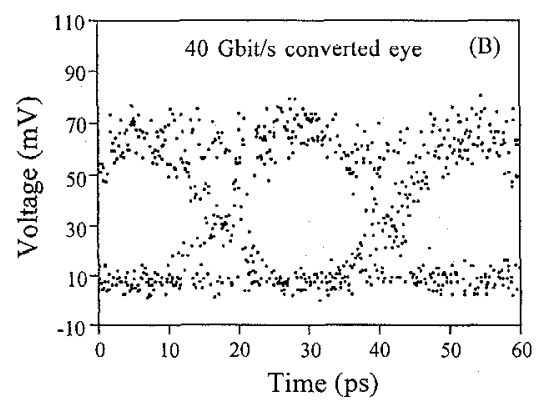

(b)

CMF4 Fig. 3 (a) BER performance of 20 Gbit/s wavelength conversion from 1555-1560 $\mathrm{nm}$ using an all-active MQW Michelson converter. Power levels are: $\lambda_{\text {conv }}=1560 \mathrm{~nm}, 9 \mathrm{dBm}$, $\lambda_{\text {in }}=1555 \mathrm{~nm}, 6 \mathrm{dBm}$. (b) $40 \mathrm{Gbit} / \mathrm{s}$ converted eye-diagram with an all-active MQW Michelson converter. Conversion from $1558-1562 \mathrm{~nm}$ is carried out. Power levels are: $\lambda_{\text {conv }}=1562 \mathrm{~nm}, 9$ $\mathrm{dBm}, \lambda_{\text {in }}=1558 \mathrm{~nm}, 8 \mathrm{dBm}$.

will enable high bit-rate operation. As a fine example of this, Alcatel has fabricated a compact (1.3 $\mathrm{mm}$ long) monolithically integrated Michelson chip using all-active multiple quantum well based layer structures that has demonstrated excellent performance at both 20 and $40 \mathrm{Gbit} / \mathrm{s}$ as shown in Fig. 3. Extinction ratios above $10 \mathrm{~dB}$ are easily reached at these high bit-rates together with signal-to-ASE ratios exceeding $25 \mathrm{~dB}$ ( $1-\mathrm{nm}$ bandwidth), which is of great importance for the cascadability. Issues of controllability of the converters are also addressed.

1. T. Duress et al., IEEE J. Lightwave Technol. 14 (1996). 